\title{
Chlamydia screening and treatment in patients undergoing evacuation of retained products of conception or vaginal termination of pregnancy: an audit of the Royal College of Obstetricians and Gynaecologists' Guidelines in practice
}

\author{
Nicole Zenner, Robin Crawford
}

\begin{abstract}
Objective To assess compliance with the Royal College of Obstetricians and Gynaecologists Guidelines regarding screening for and treatment of Chlamydia trachomatis before vaginal termination of pregnancy (VTOP) and surgical evacuation of retained products of conception (ERPC).

Methods Case notes of women undergoing VTOP and ERPC in the authors' department were examined for evidence of the presence of $C$. trachomatis infection and identification of chlamydia risk factors, and for evidence of curative treatment for women with confirmed infection or prophylactic treatment for women at risk.
\end{abstract}

Results In the VTOP group $(n=30)$ screening and treatment was carried out satisfactorily, aided by an assessment proforma. In the ERPC group $(n=30)$ there were weaknesses in the identification and treatment of patients at risk.

Conclusions We conclude that the use of a proforma helps to achieve effective screening. Adequate risk assessment of women undergoing ERPC seems to be difficult to achieve and so universal administration of prophylactic antibiotics might be a safe and efficient option until the National Chlamydia Screening Programme is established in our area.

Keywords audit, chlamydia screening, miscarriage, RCOG Guidelines, termination of pregnancy

J Fam Plann Reprod Health Care 2007; 33(2): 95-98 (Accepted 19 July 2006)

\section{Introduction}

The Royal College of Obstetricians and Gynaecologists (RCOG) issued Guidelines for The Management of Early Pregnancy Loss in 2000 (updated in October 2006) and The Care of Women Requesting Induced Abortion in 2004. These Guidelines addressed the question of bacteriological screening of the lower genital tract prior to surgical instrumentation of the uterus. 1,2

Good evidence demonstrates that surgical termination of pregnancy in the presence of underlying lower genital tract infection with Chlamydia trachomatis increases the risk of post-abortion pelvic infection leading to complications such as tubal infertility, ectopic pregnancy, chronic pelvic pain and pelvic inflammatory disease. The risk decreases significantly if either prophylactic antibiotics are given, or confirmed infections are treated, before or at the time of vaginal termination of pregnancy (VTOP) ${ }^{3,4}$ The RCOG Guidelines also advise screening for $C$. trachomatis before surgical evacuation of retained products of conception (ERPC) for missed or incomplete miscarriage in women at risk for chlamydia infection, especially women aged under 25 years. However, in this case universal prophylactic administration of antibiotics is not supported by published evidence. ${ }^{5}$ One factor that may account for the different advice may be the assumed lower risk profile in women with miscarriage in comparison to women requesting termination, although data regarding this assumption are scarce.

Department of Obstetrics and Gynaecology, Addenbrooke's Hospital, Cambridge, UK

Nicole Zenner, MD, DFFP, Specialist Registrar in Obstetrics and Gynaecology

Robin Crawford, MD, FRCOG, Gynaecological Oncologist and Audit Lead

Correspondence to: Dr Robin Crawford, Department of Gynaecology, Addenbrooke's Hospital, Hills Road, Cambridge CB2 2QQ, UK. E-mail: robin.crawford@addenbrookes.nhs.uk

\section{Key message points \\ - The use of an assessment proforma helps to identify patients at risk of Chlamydia trachomatis infection. \\ - There is a need to improve identification of women at risk of $C$. trachomatis infection undergoing surgical evacuation of retained products of conception. \\ - Universal perioperative prophylaxis might be beneficial until the National Chlamydia Screening Programme is established in our area.}

The 'woman at risk' for chlamydial infection is well described in the literature. Age is the most important risk factor, with the highest prevalence rates reported in the 16-25 years age group ${ }^{6}$ followed by the risk factor of more than two sexual partners in the previous 12 months. ${ }^{7}$ The combination of these risk factors achieves an $87 \%$ pick-up rate of chlamydia infections. Other significant risk factors include non-married status, a previous history of sexually transmitted infection (STI) and inconsistent condom use. ${ }^{8}$ Possibly as a result of inconsistent barrier contraceptive usage, the request for TOP itself was found to be a significant risk factor, and a median prevalence rate of $8 \%$ for chlamydia infection is seen in this population group. ${ }^{9}$ Studies with smaller patient numbers associate chlamydia infection with nulliparity, early school leaving age, ethnicity and low socioeconomic status at non-significant levels.

To ensure compliance with the RCOG Guidelines of offering consistent screening for chlamydia, a protocol for TOP was developed in the authors' department. However, management of elective and emergency ERPC seemed to lack the standardised approach seen with the use of a protocol, and there was a suggestion that women often did not receive appropriate screening or prophylactic treatment for chlamydia infection.

This audit examined the clinical practice of screening and treatment of chlamydia infection before instrumentation of the uterus comparing VTOP with ERPC 
Zenner and Crawford

Table 1 Identified risk factors

\begin{tabular}{lllllr}
\hline $\begin{array}{l}\text { Procedure } \\
\text { performed }\end{array}$ & $\begin{array}{l}\text { Aged under } \\
\text { 25 years }\end{array}$ & $\begin{array}{l}\text { Non-married } \\
\text { status }\end{array}$ & Previous TOP & Previous STI & $\begin{array}{l}\text { Total number with } \geq \mathbf{1} \\
\text { identified risk factors }\end{array}$ \\
\hline VTOP & $16 / 30(53.3)$ & $17 / 30(56.7)$ & $8 / 30(26.7)$ & $2 / 30(6.7)$ & $23 / 30(76.7)$ \\
ERPC & $4 / 30(13.3)$ & $2 / 30(6.7)$ & $3 / 30(10.0)$ & $1 / 30(3.3)$ & $8 / 30(26.7)$ \\
\hline
\end{tabular}

Percentage values are given in parentheses. ERPC, evacuation of retained products of conception; STI, sexually transmitted infection; VTOP, vaginal termination of pregnancy.

Table 2 Risk assessment and documentation

\begin{tabular}{lllll}
\hline $\begin{array}{l}\text { Procedure } \\
\text { performed }\end{array}$ & $\begin{array}{l}\text { Age } \\
\text { documented }\end{array}$ & $\begin{array}{l}\text { Marital status } \\
\text { documented }\end{array}$ & $\begin{array}{l}\text { Previous TOP } \\
\text { status documented }\end{array}$ & $\begin{array}{l}\text { Previous STI } \\
\text { documented }\end{array}$ \\
\hline VTOP & $30 / 30(100.0)$ & $29 / 30(96.7)$ & $30 / 30(100.0)$ & $\begin{array}{l}\text { Sexual history } \\
\text { documented }\end{array}$ \\
ERPC & $30 / 30(100.0)$ & $23 / 30(76.7)$ & $30 / 30(100.0)$ & $0 / 30(0.0)$ \\
\hline
\end{tabular}

Percentage values are given in parentheses. ERPC, evacuation of retained products of conception; STI, sexually transmitted infection; VTOP, vaginal termination of pregnancy.

in the authors' unit. Emphasis was also placed on the practice and quality of our risk assessment with regard to C.trachomatis.

\section{Methods}

The audit investigated the management of 30 women undergoing VTOP and similarly 30 women undergoing ERPC in the Department of Obstetrics and Gynaecology at Addenbrooke's University Hospital, Cambridge, UK. Consecutive cases of VTOP and ERPC in the first trimester of pregnancy were extracted from theatre lists. In March 2004, 30 VTOP and 15 ERPC were performed. A further 15 consecutive ERPC performed in January and February 2004 were therefore added to the sample in order to generate equal numbers for comparison. The case notes of all 60 women could be found and examined. For the ERPC group, the data were extracted from the entries in the patients' notes on admission to hospital as emergency cases or on referral from the ultrasound scan department. For the VTOP group, the completed proforma of the termination clinic was reviewed. This contained the gestational age of the current pregnancy, marital status, previous history of STI or VTOP, contraceptive use in the past and future, and TOP method planned, in addition to a record of performance of chlamydia screening. The results of chlamydia screening were taken from the microbiology database.

Information on age, marital status, previous TOP, history of previous STI and sexual history was collected from the above sources. Documentation of vaginal bleeding or spotting on assessment was noted. Microbiological details (chlamydia swabs) were recorded and whether or not curative or prophylactic antibiotics were given including particulars of antibiotic choice. Information was obtained about referral of patients with a positive chlamydia result to the local genitourinary medicine (GUM) clinic for follow-up and contact tracing.

The first group consisted of women requesting VTOP with a viable pregnancy diagnosed on dating scan and the second group comprised women with a missed or incomplete miscarriage undergoing instrumentation of the uterus. To review our management of women at increased risk of chlamydia infection we identified women with at least one risk factor (aged under 25 years, non-married status, more than two sexual partners within the last year, history of previous TOP and history of previous STI) and reviewed these women separately.

The percentage of women who were referred to the GUM clinic for the follow-up of a positive swab result was verified by them without breaking confidentiality. As this study was an audit of our management against RCOG standards, ethical committee approval was not required.

\section{Results}

Identified risk factors

Assessment of risk factors in the VTOP group revealed that in 23/30 (76.7\%) women at least one risk factor for chlamydia was identified. In the ERPC group we could identify at least one risk factor for chlamydia in eight $(27.0 \%)$ of the women (Table 1$)$.

\section{Risk assessment and documentation}

Notes review in both groups revealed 100\% documentation of age and previous TOP status. A sexual history was not documented in any of the cases. In the VTOP group only one set of notes lacked documentation of marital status and one lacked comment about previous STI. In the ERPC group details of marital status were missing in $7 / 30$ $(23.3 \%)$ cases and $23(76.7 \%)$ lacked information about previous STI (Table 2).

\section{Screen and treatment performance}

In the VTOP group $100 \%$ of women had chlamydia swabs performed before the procedure in keeping with the RCOG Guidelines. Of these, $70 \%(21 / 30)$ were reported as negative on the day of the procedure. Of the remaining nine women with a positive or pending result on the day of the procedure, only seven received antibiotics. Two (6.7\%) of the 30 women who underwent VTOP tested positive for chlamydia and one of them did not receive any perioperative treatment.

Table 3 Screen and treatment performance

\begin{tabular}{lllll}
\hline $\begin{array}{l}\text { Procedure } \\
\text { performed }\end{array}$ & $\begin{array}{l}\text { Bleeding/spotting } \\
\text { on admission }\end{array}$ & $\begin{array}{l}\text { Chlamydia } \\
\text { swab performed }\end{array}$ & $\begin{array}{l}\text { Negative chlamydia } \\
\text { result available on } \\
\text { operation day }\end{array}$ & $\begin{array}{l}\text { Positive, pending or } \\
\text { unavailable chlamydia } \\
\text { result on operation day }\end{array}$ \\
\hline VTOP & $0 / 30(0.0)$ & $30 / 30(100.0)$ & $21 / 30(70.0)$ & $\begin{array}{l}\text { Antibiotic treatment } \\
\text { required and given }\end{array}$ \\
ERPC & $22 / 30(73.3)$ & $7 / 30(23.3)$ & $5 / 30(16.7)$ & $25 / 30(83.3)$ \\
\hline
\end{tabular}

Percentage values are given in parentheses. ERPC, evacuation of retained products of conception; VTOP, vaginal termination of pregnancy. 
Table 4 Screen and treatment performance for women with at least one risk factor (see Table 1)

\begin{tabular}{llcll}
\hline $\begin{array}{l}\text { Procedure } \\
\text { performed }\end{array}$ & $\begin{array}{l}\text { Bleeding/spotting } \\
\text { on examination }\end{array}$ & $\begin{array}{l}\text { Chlamydia } \\
\text { swab performed }\end{array}$ & $\begin{array}{l}\text { Negative chlamydia } \\
\text { result available on } \\
\text { operation day }\end{array}$ & $\begin{array}{l}\text { Positive, pending or } \\
\text { unavailable chlamydia } \\
\text { result on operation day }\end{array}$ \\
\hline VTOP & $0 / 23(0.0)$ & $23 / 23(100.0)$ & $17 / 23(73.9)$ & $6 / 23(26.0)$ \\
required and given \\
ERPC & $6 / 8(75.0)$ & $5 / 8(62.5)$ & $3 / 8(37.5)$ & $5 / 8(62.5)$ \\
\hline
\end{tabular}

Percentage values are given in parentheses. ERPC, evacuation of retained products of conception; VTOP, vaginal termination of pregnancy.

In the ERPC group 23.3\% (7/30) had chlamydia swabs performed before the procedure, of which $5 / 7(71.4 \%)$ negative results were available on the operation day. Of the remaining 25 women with a positive, unavailable or pending chlamydia result on the day of the procedure, only one received antibiotics. In this case the woman was detected as being positive for chlamydia and received treatment prior to the procedure (Table 3 ).

\section{Management of women with at least one risk factor in the ERPC group}

As advised by the RCOG Guidelines, a 'screen and treat' policy is only recommended for women 'at risk' undergoing ERPC. ${ }^{1}$ Therefore successful screening was assessed in relation to the risk factors for chlamydia. Of the eight women identified as being at risk, five $(62.5 \%)$ had chlamydia swabs taken, with $60 \%$ (3/5) reported back as negative before the procedure. In conclusion, there were five women at risk of chlamydia infection with a positive, pending or unavailable result on the day of the procedure who should have received antibiotics. Of these, one woman with a positive result received antibiotic treatment, while four women at risk with pending or unavailable results did not receive any prophylactic antibiotics (Table 4).

\section{GUM clinic attendance}

Two out of three (66\%) women with positive chlamydia results attended the local GUM clinic for follow-up and contact tracing. Owing to the small number and the need for confidentiality, we could not assign them to their original groups.

\section{Statistical evaluation}

The statistical significance of the differences found was tested with Fisher's exact test. The difference in the number of risk factors in both groups was statistically significant as was their documentation. Identified risk factors and documentation, screening rates for chlamydia and prophylactic administration of antibiotics were all significantly greater in the VTOP group.

In the management of high-risk cases, the differences between the two groups are smaller and lack significance. In other words, within the ERPC group high-risk cases are often identified and treated appropriately despite the poor documentation.

\section{Discussion}

This audit demonstrates that the use of the termination clinic proforma allows good data collection with respect to chlamydia infection risk in women undergoing VTOP. By identifying risk factors for chlamydia in this group, we have demonstrated that patients either did not require antibiotics or that we gave the appropriate prophylaxis in all except 2/30 (7\%) cases.

However, it is evident that there is insufficient risk assessment for the group undergoing ERPC. The lack of effective chlamydia screening in the ERPC group may be due to several factors. First, the ERPC group may be perceived as a low-risk group. According to our risk estimation (Table 1) this group does show significantly fewer risk factors compared to the VTOP group, especially with regard to age (i.e. $87 \%$ were aged over 25 years). ${ }^{7}$ Because of low screening rates in our ERPC group, prevalence rates for chlamydia cannot be deduced from our results. In the literature there are only scarce and conflicting data available regarding this question. Macmillan et al. found similar chlamydia prevalence rates in women attending for miscarriage $(4.0 \%)$ and for TOP $(5.7 \%)$, while Shankar et al. described much lower rates for women presenting to an early pregnancy unit $(1.96 \%) .6,10$ Obviously further research is needed to confirm prevalence numbers for this group in our population.

Second, in over $70 \%$ of the ERPC group vaginal bleeding or spotting on admission was documented; this may have been perceived as a contraindication to taking endocervical swabs for chlamydia. Although the exact numbers of false-negative tests in this setting are still to be researched, this method of testing is currently the accepted standard. ${ }^{11}$ Vaginal bleeding should not be a reason for omitting swabs in this scenario and further education regarding this is needed in our department.

Third, awareness with regard to $C$. trachomatis and the subsequent risk of ascending infection is not high enough in our department, leading to insufficient history taking and screening. Even in the well-screened VTOP group, the team failed to administer antibiotics to one chlamydia-positive woman. Certainly education is needed in this area also.

Ensuring that all women have their chlamydia status checked and having the result available before instrumentation of the uterus would be an appropriate standard for us to achieve. Unfortunately the length of time between taking a swab and the final procedure is less predictable and usually shorter for ERPC compared to VTOP. Therefore it will prove difficult to get swab results back from the laboratory in time in all cases.

Studies comparing universal prophylaxis with a 'screen and treat' policy before VTOP indicate decreased postoperative morbidity and costs for the prophylaxis group. However, the issue of partner notification and reinfection is not addressed by this method. The combination of screening and universal prophylaxis would be ideal, providing safety for the individual patient and improving long-term health for the community at the same time. ${ }^{12}$

At present we feel that women who have an early pregnancy loss with a subsequent surgical ERPC should have prophylactic antibiotics at the time of the procedure independent of their risk profile. This may represent the most efficient use of our resources, rather than the sporadic taking of microbiological samples, the results of which are not always available at the time of the surgery. Once the National Chlamydia Screening Programme is established in our region, our practice will certainly need to be reviewed and modified accordingly. Such screening should provide valuable data regarding our local chlamydia prevalence rates and will therefore aid our decisions regarding prophylactic treatment. 


\section{Acknowledgements}

The authors would like to thank the staff at their GUM Clinic and Early Pregnancy Unit for help and advice.

Statements on funding and competing interests Funding None identified.

Competing interests None identified.

References

1 Royal College of Obstetricians and Gynaecologists (RCOG). The Management of Early Pregnancy Loss (RCOG Green Top Guideline No. 25). London, UK: RCOG Press, 2000; 1-14. NB. This has been superseded by the the second edition of The Management of Early Pregnancy Loss (RCOG Green Top Guideline No. 25), which was published in October 2006 after completion and acceptance of this article. http://www.rcog. org.uk/resources/Public/pdf/green_top_25_management_epl. pdf [Accessed 14 February 2007].

2 Royal College of Obstetricians and Gynaecologists (RCOG). The Care of Women Requesting Induced Abortion (Evidencebased Clinical Guideline Number 7). London, UK: RCOG Press, 2004; 1-115. http://www.rcog.org.uk/resources/Public/ pdf/induced abortionfull.pdf [Accessed 14 May 2006].

3 Sawaya GF, Grady D, Kerlikowske K, Grimes DA. Antibiotics at the time of induced abortion: the case for universal prophylaxis based on meta-analysis. Obstet Gynecol 1996; 87(5 Pt 2): 884-890.

4 Penney GC, Thomson M, Norman J, McKenzie H, Vale L, Smith R, Imrie M. A randomised comparison of strategies for reducing infective complications of induced abortion. $\mathrm{Br} J$
Obstet Gynaecol 1998; 105: 599-604

5 Prieto JA, Eriksen NL, Blanco JD. A randomized trial of prophylactic doxycycline for curettage in incomplete abortion. Obstet Gynecol 1995; 85: 692-696.

6 Macmillan S, McKenzie H, Flett G, Templeton A. Which women should be tested for Chlamydia trachomatis? $\mathrm{Br} \mathrm{J}$ Obstet Gynaecol 2000; 107: 1088-1093.

7 LaMontagne DS, Fenton KA, Randall S, Anderson S, Carter P. Establishing the National Chlamydia Screening Programme in England: results from the first full year of screening. Sex Transm Infect 2004; 80: 335-341.

8 Fenton KA, Korovessis C, Johnson AM, McCadden A, McManus S, Wellings $\mathrm{K}$, et al. Sexual behaviour in Britain: sexually transmitted infections and prevalent Chlamydia trachomatis infection. Lancet 2001; 358: 1851-1854.

9 Chief Medical Officer. Summary and Conclusions of CMO's Expert Advisory Group on Chlamydia trachomatis. London, UK: Department of Health, 2001; 1-22.

10 Shankar M, Dutta R, Gkaras A, Tan B, Kadir RA, Economides D. Prevalence of Chlamydia trachomatis and bacterial vaginosis in women presenting to the early pregnancy unit. J Obstet Gynaecol 2006; 26: 15-19.

11 Logan S, Browne J, McKenzie H, Templeton A, Bhattacharya S. Evaluation of endocervical, first-void urine and selfadministered vulval swabs for the detection of Chlamydia trachomatis in a miscarriage population. Br J Obstet Gynaecol 2005; 112: 103-106.

12 Cameron ST, Sutherland S. Universal prophylaxis compared with screen-and-treat for Chlamydia trachomatis prior to termination of pregnancy. Br J Obstet Gynaecol 2002; 109: 606-609.

\section{FACULTY MEMBERSHIP EXAMINATION}

The Membership Examination (MFFP) consists of:

\section{Part 1 Multiple Choice Question Paper (MCQ)}

This 11/2-hour paper consists of 50 clinical science and applied science questions.

The examination will be held in London on Friday 19 October 2007 (applications must be received by 1 July 2007). The application form and information on the Part 1 can be obtained from the Faculty of Family Planning website (www.ffprhc.org.uk).

\section{Dissertation or Case Reports}

Submission of one Dissertation (10 000 words) or two Case Reports (3000 words each).

Please visit the Faculty of Family Planning website (www.ffprhc.org.uk) for the latest changes to this part of the examination, and for information on exemptions.

\section{Part 2 Examination (CRQ, MEQ, OSCE)}

This all day examination consists of:

Critical Reading Question examination paper (CRQ)

Modified Essay Question examination paper (MEQ)

Objective Structured Clinical Examination (OSCE)

Applications for the MFFP Part 2 held in June 2008 must be received by 3 January 2008. Please consult the revised Examination Regulations for changes to the entry requirements. Information on the Part 2 examination and the application form appear on the Faculty of Family Planning website (www.ffprhc.org.uk).

The qualification is subject to re-certification every 5 years.

For the revised MFFP Examination Regulations (December 2005), information and application forms please visit the Faculty of Family Planning website: www.ffprhc.org.uk (see Training \& Exams and MFFP Member). Also available on request from: Mrs Denise Pickford, Examinations, Faculty of Family Planning and Reproductive Health Care of the Royal College of Obstetricians and Gynaecologists, 27 Sussex Place, Regent's Park, London NW1 4RG, UK. Tel: +44 (0) 2077245629. Fax: +44 (0) 207723 5333. E-mail: denise@ffprhc.org.uk 